\title{
Supporting decision making in disasters: the DiMas Tool
}

\author{
Eran Lederman ${ }^{1}$ and Luisa Chimenz $^{2}$ \\ ${ }^{1}$ Bezalel Academy of Arts and Design, Jerusalem, Israel \\ lederan@gmail.com \\ ${ }^{2}$ Department Architecture and Design, University of Genoa, Italy \\ luisachimenz@arch. unige.it
}

\begin{abstract}
Disasters leave a trail of destruction, casualties and ruined human lives. They can directly cause loss of life and injury, destroy cities, buildings, living and public spaces, and damage vital infrastructures necessary for everyday functions. The aims of this essay are to present the research tool, in its on-going and yet undefined configuration, and at the same time for involving the many time ICT aspects and challenges of coping with disaster risk reduction and relief, definitely necessary in the operational and disseminating phases beyond the tool itself. Within the paper, along with the exposition of our idea in its actual form which considers the possibility of further variations - we will present the reasons of the whys and reach to descript how we do believe the tool should be, passing through the other major issues like the who and the what. The tool is intended to be structured as the outcome of an applied research project, for creating a decision supporting instrument which will enable a broad range of relevant stakeholders to choose the most suitable sheltering solution, dwelling unit or machinery needed. The DiMaS Tool research project aims to present itself as a possibility for sorting and mapping already existing ready-to-use solutions, by specific parameters and characteristics, creating a taxonomy and a related system and expressing it in a universal and understandable language, through the ICT skills, in order to help choose the most adequate answer, managing the implementation and responsive process quickly and effectively.
\end{abstract}

Keywords: Design for Disasters, Disaster Relief Resilience and Research, Emergency preparedness.

\section{Introduction}

Disasters leave a trail of destruction, casualties and ruined human lives. Their oc-currence can directly cause loss of life and injury, accidentally can seriously affect and destroy cities, buildings, living and public spaces, as well damaging vital infra-structures necessary for everyday functions. The UNISDR Ten Essentials guide us, as researchers and experts, interested at the many operative level of Disaster relief and mitigation, in preparing and planning key elements for an effective response during and after a strike of a disaster. The Essentials, in fact, allow for quick, organized response vital for dealing and preventing the devastating consequences of disasters, in order to restore a meaning of 'normality' and even Build Back Better (BBB). 
This nodal concept has been largely treated in the many different areas that deal with disaster effects mitigation [19] [30] and can be accomplished by creating a 'pre-vention culture', letting preparedness for emergency assume its correct role, consider-ing rehabilitation mechanisms something that is within and can be considered before. If these latter, nevertheless, are pivotal tools for managing potential disasters and their consequences in case of occurrence, it's a fact that good response and qualita-tive relief depart from the inherent possibility of being ready in advance [21].

If we do agree with the Practical Action that: «Disasters only occur when a natural hazard arises in vulnerable conditions» $[25,1]$ we still have to consider that in case of the occurrence of a disaster there is a variety of factors to be faced and with which every actor on the field, form the decision makers to the citizen, has to cope with. According to the Gaillard and Mercer, in fact:

«Most national risk reduction policies still rely on command-and-control and topdown frameworks, which emphasize scientific knowledge and national government intervention at the detriment of local actions. Only within the international arena have policy-makers considered ideas from the vulnerability paradigm. This led to the development of international policy documents, such as the Hyogo Framework for Action (HFA). However, such a non-binding treaty with no concrete targets remains too vague to entail concrete outcomes at the national level.» $[11,94]$

Finally, it is not so simple, in the end and even in the so-called advanced society hazards and consequent disasters create a deep change in the geography of everyday lives and the concept of Building Back Better is nodal to the correct repositioning of a natural life-cycle of complex environment. More than scientific essays in the words of those affected by a disaster, like we experienced on the field in the occurrence of the earthquake in central Italy in October 2016, there is the need for a new beginning, the possibility of feeling the Governmental support passes and somehow can be measured by the qualitative perception of the aiding activities in time.

On the other hand, when considering the aiders on the field we experienced the same feelings of discomfort in regard of the lack of information and coordination and the need of a supporting tool, to get and share information with effectiveness.

In fact, as expressed by Zlatanova, Crompvoets and Scholten:

«To fight the incident, safe lives and restrict the damaging consequences of the disaster, first responders of emergency forces go into action, i.e. the fire brigades, the police forces, paramedics and the government. These emergency forces have their own tasks, but they need to cooperate for effective disaster fighting.» [36, 1-2]

As well, on another side, it's here proper to refer to the words of Kapucu and Garayev saying:

«Because if the uncontrollable and consequential nature of disasters affecting masses of people and requiring involvement of various sectors, organizations, and stakeholders, collaboration plays an important role to achieve ultimately successful results. It is equally inevitable for different entities to collaborate in order to increase response effectiveness and reduce casualties.» $[16,368]$

The whys of this paper, therefore, and of the on-going research work behind, are for supplying the demand for tailored and proper response, alongside the realization that there are already several existing ready-to-use solutions. This suggests the need for a 
system to better optimize adequate response, within the range of existing solu-tions, to cope in different disaster areas and with dissimilar disaster types. Within a wide range and a great variety of possibilities, supplying ineffective, unsuitable inhab-iting solutions and connected services units, underestimating the cultural needs can delay, harm and deeply affect for the deterioration the rehabilitation process.

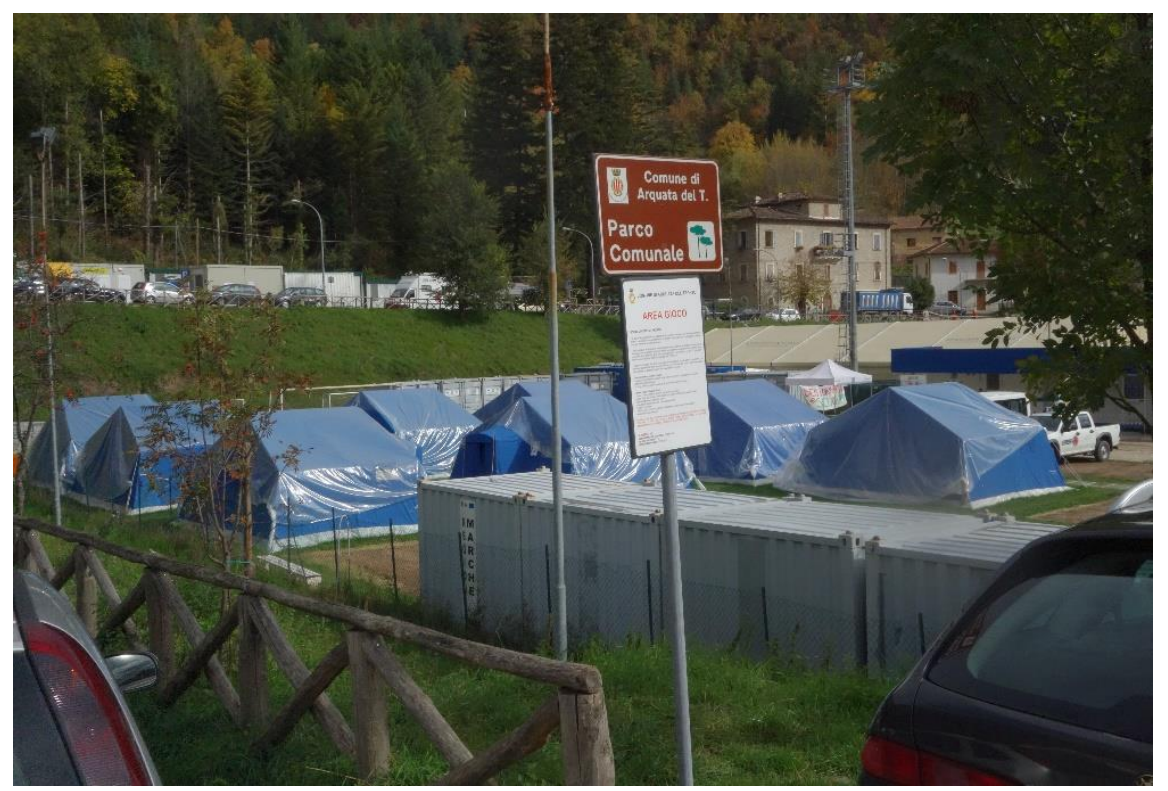

Fig. 1. Arquata del Tronto, Italy, October 2016; tents provided to volunteers operating in the earthquake's area of central Italy, by Civil Protection. Containers are used as storage and as sanitary services.

\section{Methodology}

In the occurrence of a disaster, government agencies, local authorities, international aid organizations and non-profit organizations do their best to supply quick and effective responses to the dwelling problem that immediately arises. Diverse ide-as, solutions and resources are often directed to disaster areas, in an attempt to meet the needs of the community and address the crisis as fast as possible, and this is especially true more in the cases of occurring of a disaster in developing countries and less industrialised, than in 'richer' societies, it could be argued.

This paper wishes to present an innovative research tool, in its on-going and undefined yet configuration, based on design thinking experience and knowledge and dealing with the consistent conviction of the contribution that the design discipline may add to the issue; for sure, it has to be provided of a multi-disciplinary sight, by conveying in it necessarily research works, as well as concepts and inspirations from the variety of disciplines interested in facing the disaster response and relief and time. 
For this reason the literature review has been extensive and vast, departing from keywords, i.e. disaster managing, design and disaster, the results convey together from Psychology to ICT aspects, of course.

We strongly believe that, as said by Gaillard and Mercer, about the multilayer operational support on the field and that:

"We hereby suggest that DRR should be inclusive rather than exclusive. Here 'inclusive' means (1) recognizing that different forms of knowledge are valuable in addressing disaster risk, (2) that actions at different scales, from the top down and from the bottom up, are necessary to reduce the risk of disaster in a sustainable manner, and (3) that both previous points require a large array of stakeholders operating across different scales to collaborate.» $[11,95]$

Indeed, we do believe - after the literature examination - the compulsory prerequisite to set under the umbrella of design thinking either for a multidisciplinary approach either for involving as a basis the many time ICT aspects; otherwise the challenges of coping with disaster risk reduction and relief, couldn't be definitely satisfied, as for necessary in the operational and disseminating phases beyond the tool itself. Many researches and studies have shown that adequate and tailored dwelling and responsive solutions (whether for the short or long term) can have a great impact on the rehabilitation process of individuals as well as the community as a whole.

The tool we have in mind will respond to a precise idea of sharable and understandable data source: even if the architecture behind will be, of course, necessarily, articulated and layered, the tool itself will appear easy to be used and consulted at its best. We do think it shall be structured as the outcome of an applied research project, for creating a decision supporting tool which will enable a broad range of relevant stakeholders to choose the most suitable sheltering solution, dwelling unit or machin-ery needed. Thus, as for its multidisciplinary aspects, already highlighted and also reinforced by the literature examination, in which evidently different sources con-verge on one single articulated issue, the tool requires to be composed with the contri-bution of geographers, anthropologists, engineers, economists, psychologists, archi-tects, urbanplanners, designers, organization consultants, disaster managers and, last but not least, the communities interested by the disaster, as for the importance of their know-how as end-users.

If we want to consider the problem in its real application, for instance this has been an enormous problem in the occurrence of the earthquake in the regions of central Italy, in 2016, as the dwelling units were not ready to be conveyed on the site, the necessary operational systems, perfectly working in the immediate emergency tended to lack with the advancement of months and for responding to the Winter season and in addition. after a short while, the dwelling units, here solved as small wooden houses revealed not to be completely proper to the requirements of the territory.

All of the who on the field and before should find in the common sharable chose language an answer and the needed information to better address and 'read' the territory, the emergencies on the field and the disaster to be faced.

Nonetheless, it is here proper to report that many researches have been in the past ten-fifteen years conducted over the possibility of supporting tools, and even experienced and tested on the field but as reported by Ochoa, Neyem, Pino and Borges 
many of these systems have failed when in action [23] because they do lack in communicational effectiveness and operability or they do not consider the many different possibility of the users. The authors, in fact, highlight that:

«The problems related to decision delivery and implementation are based on the lack of an inter-organizational structure able to establish responsibilities and decision making levels.» [23, 149]

In addition, it might be said with the words of Gaillard and Mercer that:

«For example, solutions offered by a DRR effort based on solid scientific parameters may fail for not fitting within local wisdoms, whereas solutions based on contextual specific local knowledge may fail in light of the increased pace of change experienced today. Hence there is an obvious need to combine the most effective and applicable local and scientific knowledge. A technical know-how adapted to local wise practices could greatly enhance DRR strategies.» $[11,96]$

In fact, whilst we observe a wide range and a great variety of solutions, especially of dwelling solutions for the longer terms and the so-called 'second emergency', we have to take into account that everyone of them actually responds with its own features, meeting only determinate requirements.

These requirements, often, consider or are the basis for choosing and designing the operative solution and may go from the compatibility to different climate zones, or topographic and geographic structures of the territories, the direct costs of the dwelling unit and the additional ones for putting in service; as well, the requirements are related to the size, materials, the complexity either architectural and internal either for assembling/deploying it and, last but not least, the time, efforts and expertise which are needed for the implementation in situ.

Probably it is wrong to say that any possible solution has been designed and produced, and every time that a new dwelling unit demonstrate its effectiveness, here it comes again the question if there is or there could ever be the 'one' and the 'best' unique solution. Actually, in our previous studies, we have already demonstrated that the nature of the disaster but also the climate zone in which this occurs, as well as the territorial structure along with the community one determinate different needs [8].

Supplying ineffective, unsuitable inhabiting solutions and connected services units, underestimating the cultural needs can delay, harm and deeply affect the rehabilitation process. The demand for tailored and appropriate response, alongside the realization that there are already several existing ready-to-use solutions, suggests the need for a system to better optimize suitable reaction, within the range of existing solutions, to cope in different disaster areas and with dissimilar disaster types.

Within the development of the DiMas tool, therefore while there would be no need to define the disasters as we will refer to the ones already identified by the UNSDR, there will be the necessary definition of other parameters that will care about the issues cited above.

It is envisioned, hence, that a decision-support tool will enable the relevant stakeholders, to identify through determined classes of types and ranges the most relevant solution, for the certain needs ensuring effective disaster response to the specific situation. 
In the structuring operational activities of this tool, that we called the DiMas tool, the ICT technology plays a crucial and fundamental role. ICT technology is, in fact, the path to manage and gather together information before, as for inserting all the needed data in the tool to make it work, and at the same time IT structuring skills are fundamental for making the DiMas tool working as a dissemination instrument and as an operational support.

Actually the closest research work, that is here worth to cite, made by Ochoa, Neyem, Pino and Borges describes:

«... a proposal to include first responders as decision makers and it describes a technological platform to record, represent and distribute contextual information during disaster relief efforts. The platform intends to improve the decision-making and coordination processes among first responders and the command post. The plat-form is composed of a software, hardware and communication system. It runs on mobile computing devices and it allows two information representations. Visual representations support the decision-making during disaster relief efforts, and the digital (internal) representation ensures the information's interoperability. The communication support enhances the communication and coordination capabilities of participant organizations. The platform also includes the support for information delivery in heterogeneous technological scenarios.» $[23,146]$

Even if the work appears very close to our own one, we argue to say it lacks the design point of view, in the meaning of a consistent perspective about the users of dwelling units and their effective adequateness to the scenario.

We imagine the tool able to provide relevant information, almost immediately, such as availability, response time, costs and, at the same time, taking into consideration even different parameters such as cultural compatibility, adaptability, transportation requirements in terms of time and, not less important possibility to be delivered in short time.

In fact, in average distinctions made in particular for dwelling unit, two are the ways of intending and looking at the solutions [8] [37]: one of them categorises the units according to their structural consistency and so identifies hard casing and flexi-ble casing; the other one, presented by Zanelli [37] examines the dwelling units ac-cording to their inner possibility of moving, distinguishing transportable, semi-transportable and self-moving,

In addition to this preliminary research work, even in the case based on the studies and the research works we had the chance to conduct in the years before, the aim is to highlight the importance of a supporting tool, properly built through the collection and systematization using the IT involvement for reaching an adequate prepared-ness, in order to better cope with disasters in the case of occurrence.

The DiMas tool, as for its multi-disciplinary aspects, recalls indeed different sources in one unique issue: for this reason the tool requires to be structured with the contribution of many disciplines as even explained before and has to be understand-able and sharable for all of them, safeguarding each disciplines' features, but com-pulsory communicating in a common language for a single meaning. 
Thus, one of the issue we think can be nodal: too often, unfortunately we face an enormous quantity of data which analysis needs and can take an amount of time, unfortunately not available in time of emergency. So we do strongly believe, that what will not work during routine times, will not work during an emergency. Again, so, it is clear how important is the preparation in advance of an adequate managing of the tool, in order to first of all highlight the lacks within, being able to implement and correct the results in 'routine' time and as well in order to conduct appropriate training that may allow an easier usage on the field in a condition of stress and pressing.

In fact, if it is true what Ochoa, Neyem, Pino, and Borges say, placing the issue at the basis of their paper and research, is even one of our major concern that:

«For that reason, the availability and understandability of the contextual information that supports the decision process should be high. Compiled information with a graphical representation (e.g. teams' location, task assignments and resource allocation presented on a map) can be used to be easy to understand by persons making decisions in different organizations.» [23, 149]

For these reasons, we talk about collaborative images and pictograms, to be used as a simple structuring language that may be accompanied by lettering, which we all know not always will be understood. Writing, hence, will be a problem, if we consider the lack of time in emergency and, more than this that not everyone of us share the same language and even alphabet.

Images are everywhere, in nowadays life, and their power is strengthened and demonstrated by the massive use. Images, anyway, after their codification in understandable pictograms, whose significance today anyone (apparently) knows are widely used as a language, sharable and - maybe - not a matter of misunderstanding. Anyhow, the many different targets and users whom enter in contact with collaborative images on the field, within the emergency reasons of a disaster, require from the design point of view a further research discourse and development observation, in particular to avoid cultural misunderstanding that again can harm all the process. 


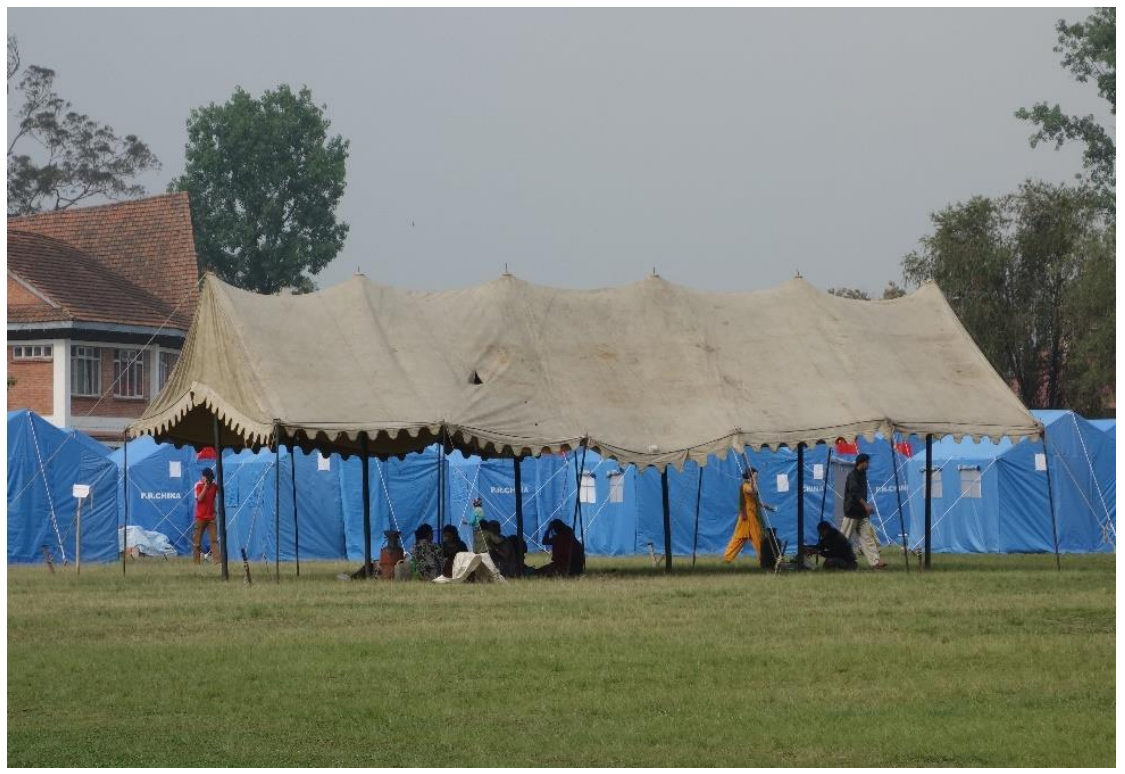

Fig. 2. Katmandu, Nepal, May 2015; blue tents provided by the P.R. of China on the back, with uncertain collective coverture as a social area.

\section{Conclusions (and expected results)}

One of the biggest and longest lasting problems in disaster areas is homelessness, as a result of the disaster itself. Being forced to leave one's own house, becoming homeless can have devastating results: it is more than mere property loss. It is related to experiencing the loss of personal and financial security. The stress caused by the situation and uncertainty of the future can endanger personal behaviour in everyday life, the strength of the family structure and the fabric of the affected and neighbours com-munities.

As in the thought of Ochoa, Neyem, Pino and Borges: "When extreme events af-fect urban areas the response process should be fast and effective because the popu-lation and civil infrastructure densities potentially increase the impact of such events. These situations have shown the need to improve the group decision making process and the coordination of relief activities carried out by relief organizations.» [23, 143]

At the same time, it's worth to remember what Kapucu and Garayev highlight in their research work:

«Decision-making in emergencies requires non-traditional approach and tools characterized by non-hierarchical structure and flexibility. The dynamic environment of disasters makes it imperative to invest in inter-sector and inter-agency cooperation and coordination» $[16,366]$

Indeed, the DiMas Tool is thought and expected for being structured as the out-come of an applied research project, for creating a decision supporting tool which will enable a broad range of relevant stakeholders to choose the most suitable sheltering solution, dwelling unit or machinery needed. 
The project, in our idea of structuring it, will sort and map existing ready-to-use solutions, by specific parameters and characteristics, creating a taxonomy and a related system and expressing it in a universal and understandable language, in order to help for choosing the most adequate answer, for managing the implementation and re-sponsive process quickly and effectively.

And additional effect, in undertaking this aim, is that the project will be able to identify possible deficiencies in already existing responses, thus becoming an inspira-tion for designers, engineers city managers and citizens.

As for the how of our designing development of the DiMaS Tool research project we are not leaving behind our experience on the field, well expressed by Gaillard and Mercer:

«Top-down policies have largely failed to prevent the occurrence of disasters, thus prompting practitioners supported by some social scientists to suggest an alternative, bottom-up framework for reducing disaster risk.» [11,97]

About the representation and the language to be used we are still undertaking these serious efforts, because as for the design discipline perspective we do ask ourselves if in the era of emoji and visual narrative, is there still place for conceptualized iconographic representation and iconological additive process, so long beloved?

According to our previous experience, we do expect that using pictograms and an additive system for structuring a DRM tool, could go along with the compulsory and needed help of personal reading and interpretation in understanding the path of reality, and for these further researchers on the field with the actors-aiders will be a demand.

As long so, if we can consider images capable to form the knowledge, the knowhow and the knowing and able to become a sharable and understandable language, as well in this process we are automatically encompassing a personal and individual knowledge procedure that mind operates to transform an iconographic language in readable and operational concepts together with the required creative work, beyond personal and common archetypes, to picture again physical solutions and their ad-herence to the issue. This is what we do link with the concept of preparedness and being trained already in the case of the occurrence of a disaster.

According that the images as visual artefacts, are 'designed objects', in the design process the final user has to be taken into account, in our opinion, to accomplish his/her background, necessary in sustaining the creativity to fill the gaps which might undermine and override all the efforts to communicate concepts and bring them from reality to abstraction and back.

We found ourselves agreeing with Kapucu and Garayev, saying that:

«The increase of frequency and scope of natural and human-made disasters dur-ing last decades made it clear that traditional emergency, crisis, and disaster man-agement tools have proved to be ineffective.» $[16,366]$

Again, in their work, as already said very close as for its basis - but anyhow dissimilar for its development and results - to our own one we found exemplary that:

«When decisions are to be made by a certain agency or coordinating body, it is crucial to have a comprehensive mechanism that would facilitate and enhance deci-sion- 
making process through various administrative, structural, and behavioral changes and adjustments.» $[16,368]$

These papers aims to highlight the importance of fostering our research methods and developing it with the needed interdisciplinary skills and multidisciplinary accents to obtain as a result a very complex outcome, easily understandable, and more easily sharable and applicable on the field in the case of the occurrence of a disaster.

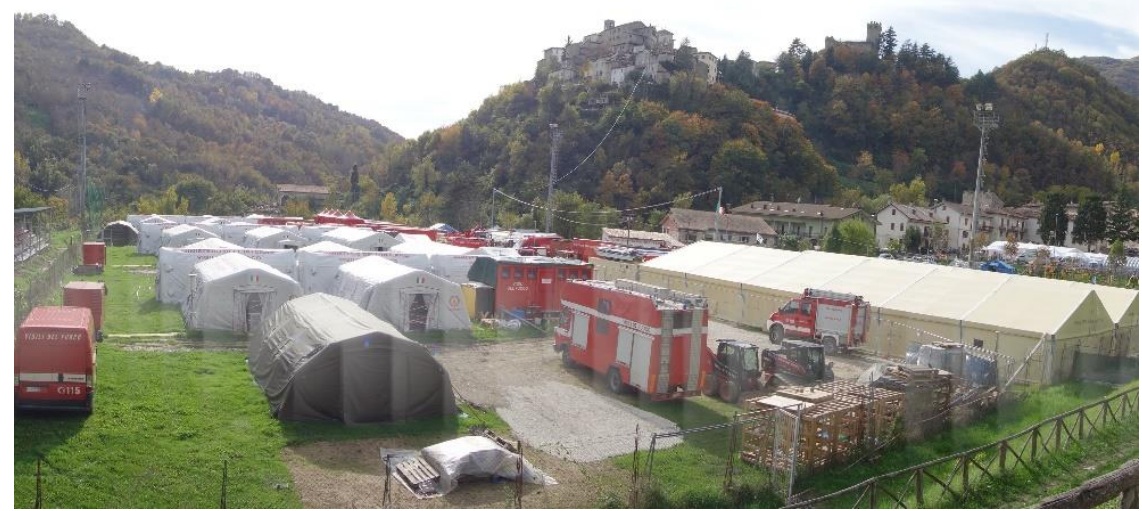

Fig. 3. Arquata del Tronto, Italy, October 2016; tents and machineries in the camp belonging to Italian Fireman, illustrating variety of structures and provisions.

Authors Contributions. The research here presented and the concept behind this work is directly and equally divided between the two authors, and part of an on-going research featured with international partners.

\section{References}

1. Adhitya, A., Srinivasan, R., Karimi, I.A.: Supply Chain Risk Identification Using a HAZOPBased Approach. AIChE Journal 55(6), 1447-1463 (2009).

2. Baek, J. S., Meroni, A. and Manzini, E.: A socio-technical approach to design for community resilience: A framework for analysis and design goal forming. Design Studies 40, 60-84 (2015).

3. Bergdoll, B., Christensen P. Home Delivery - Fabricating the Modern Dwelling. Birkhäuser, Basel-Boston-Berlin (2008).

4. Brower, C., Mallory, R., Ohlman, Z. Experimental Eco-Design: Architecture / Fashion / Product. RotoVision, Mies (2005).

5. Buchanan, R.: Design Research and the New Learning. Design Issue 17 (4) , 3-22 (2001).

6. Chamlee-Wright, E. and Storr, V. H.: Social capital as a collective narrative and post-disaster community recover. The sociological review 59(2), 266-282 (2011). 
7. Chen, L.C., Liu, Y.C., Chan, K.C.: Integrated community-based disaster management program in Taiwan: A case study of Shang-An Village. Natural Hazards 37(1-2), 209-223 (2006).

8. Chimenz, L.: Il Design Stra/ordinario. Ricerche, studi e progetti per abitare l'emergenza. di Scaranari Editore, Ferrara (2010).

9. Combaz, E.: Disaster resilience: Topic guide. Governance and Social Development Resource Centre (GSDRC), University of Birmingham, Birmingham (2014).

10. Dymon, U.J.: An analysis of emergency map symbology, International Journal Emergency Management 1 (3), 227-237 (2003).

11. Gaillard, J.C., Mercer, J.: From knowledge to action: Bridging gaps in disaster risk reduction. Progress in Human Geography 37(1), 93-114 (2012).

12. Haider, H., Mcloughlin, C. and Scott, Z.: Topic Guide on Communication and Governance. Governance and Social Development Resource Centre (GSDRC), University of Birmingham, Birmingham (2011).

13. Höppner, C., Whittle, R., Bründl, M. et al: Linking social capacities and risk communication in Europe: a gap between theory and practice? Natural Hazards 64, 1753-1778 (2012).

14. Jones, L., and Tanner, T.: 'Subjective resilience': using perceptions to quantify household resilience to climate extremes and disasters. Regional Environmental Change 17(1) 229-243 (2017).

15. Kahn, S.: Helpdesk Research Report: Community Participation in Disaster Rehabilitation and Recovery 30.05.08. Governance and Social Development Resource Centre (GSDRC), University of Birmingham, Birmingham, 1-9 (2008).

16. Kapucu, N. \& Garayev, V.: Collaborative Decision-Making in Emergency and Disaster Management. International Journal of Public Administration 34, 366-375 (2011). Routledge, Abingdon-on-Thames.

17. Manzini, E.: Design, When Everybody Design: An introduction to Design for Social Innovation. MIT Press, Cambridge - London (2015).

18. McQuaid, M.: Shigeru Ban. Phaidon, New York (2003).

19. Meroni, A. and Sangiorgi, D.: Design for Services. Routledge, Abingdon-on-Thames (2011).

20. Murphy, B. L.: Locating social capital in resilient community-level emergency management. Natural Hazards 41(2), 297-315 (2007).

21. Nakagawa, Y., Shaw, R.: Social Capital: A Missing Link to Disaster Recovery. International Journal of Mass Emergencies and Disasters 22(1), 5-34 (2004).

22. Norris, F. H., Stevens, S. P., Pfefferbaum, B., Wyche, K. F., and Pfefferbaum, R. L.: Community resilience as a metaphor, theory, set of capacities, and strategy for disaster readiness. American journal of community psychology 41(1-2), 127-150 (2008).

23. Ochoa, S.F., Neyem, A., Pino, J.A., Borges, M.R.S.: Supporting Group Decision Making and Coordination in Urban Disasters Relief (2007). Journal of Decision Systems 16 (2) 143172 (2012).

24. Papanek, V.: Design for the Real World: Human Ecology and Social Change (reprinted 2011). Thames \& Hudson, London (1984).

25. Patterson, O., Weil, F. and Patel, K. 2009. The Role of Community in Disaster Response. Popul Res Policy Rev 29 (2010), 127-141.

26. Paulheim H. et al: Improving Usability of Integrated Emergency Response Systems: The SoKNOS Approach, http://www.heikopaulheim.com/docs/informatik_2009.pdf, last accessed 2017/10/25.

27. Practical Action, The Schumacher Centre, England: Defining the community's role in disaster mitigation, http://repo.floodalliance.net/jspui/bitstream/44111/1230/1/ 
DEFINING\%20THE\%20COMMUNITY\%20ROLE\%20IN\%20DISASTER\%20

MITIGATION.pdf, last accessed 30/05/2017.

28. Ralf, M.: (ed.): Design Research Now. Essays and Selected Projects. Birkhäuser, Basel Boston - Berlin (2007).

29. Rittel, H. W.: The reasoning of designers. IGP, Montreal (1987).

30. Sanders, E. B. N., and Stappers, P. J.: Co-creation and the new landscapes of design. Codesign 4(1), 5-18 (2008).

31. Schryen, G., \& Wex, F.: Risk Reduction in Natural Disaster Management Through Information Systems: A Literature Review and an IS Design Science Research Agenda. International Journal of Information Systems for Crisis Response and Management (IJISCRAM), 6(1), 38-64 (2014).

32. Shah, F., Ranghieri, F.: A Workbook on Planning for Urban Resilience in the Face of Disasters: Adapting experiences from Vietnam's Cities to Other Cities. The World Bank, Washington D.C (2012).

33. Solo, T. M., Godinot, M. and Velasco, O.: Community Participation in Disaster Management: Reflections on Recent Experiences in Honduras and Nicaragua. In Rawlings, S., Thinking out loud IV: innovative case studies on participatory instruments, S. Rawlings, et al. The World Bank, Washington D.C, 19-26 (2003).

34. United Nation Plan of Action on Disaster Risk Reduction for Resilience, Towards a RiskInformed and Integrated Approach to Sustainable Development, United Nations (2017).

35. Von Vegesack, A., Bajetta, E.: Jean Prouvé: The poetics of the technical object. Skira, Geneva-Milan (2007)

36. Weichselgartner, J., Kelman, I.: Geographies of resilience: Challenges and opportunities of a descriptive concept. Progress in Human Geography, 1-19 (2014).

37. Zanelli, A.: Trasportabile/Trasformabile. Idee tecniche per architetture in movimento, Libreria CLUP, Milano (2003).

38. Zhang, D., Zhou, L. \& Nunamaker Jr, Knowledge and Information System 4, 370-385 Springer-Verlag, London (2002).

39. Zlatanova, S., Crompvoets, J., Scholten, H.: (2007) Spatial Data Infrastructure for emergency management: the view of the users, https://www.researchgate.net/publication/40106306, last accessed 2017/10/10. 